\title{
Candidate Biomarkers of Liver Fibrosis: A Concise, Pathophysiology-oriented Review
}

\author{
Mattia Bellan*1,2,3, Luigi Mario Castello ${ }^{1,4}$ and Mario Pirisi ${ }^{1,5}$ \\ ${ }^{1}$ Department of Translational Medicine, Università del Piemonte Orientale UPO, Novara, Italy; ${ }^{2}$ Division of Internal Medicine, \\ "Sant'Andrea Hospital", Vercelli, Italy; ${ }^{3}$ IRCAD, Interdisciplinary Research Center of Autoimmune Diseases, Novara, Italy; \\ ${ }^{4}$ Emergency Medicine Department, "AOU Maggiore della Carità", Novara, Italy; ${ }^{5}$ Division of Internal Medicine, "AOU Maggiore \\ della Carità, Novara, Italy
}

\begin{abstract}
Repair of sustained liver injury results in fibrosis (i.e. the accumulation of extracellular matrix proteins), and ultimately the complete distortion of parenchymal architecture of the liver, which we call cirrhosis. Detecting and staging of fibrosis is thus a mainstay in the management of chronic liver diseases, since many clinically relevant decisions, such as starting treatment and/or monitoring for complications including hepatocellular carcinoma, may depend on it. The gold standard for fibrosis staging is liver biopsy, the role of which, however, is questioned nowadays because of cost, hazards and poor acceptance by patients. On the other hand, imaging techniques and/or measurement of direct and indirect serum markers have not proved to be completely satisfactory under all circumstances as alternatives to liver biopsy. Making progress in this field is now more crucial than ever, since treatments for established fibrosis appear on the horizon. Fine dissection of the pathways involved in the pathophysiology of liver diseases has put forward several novel candidate biomarkers of liver fibrosis, such as growth arrest-specific6, Mac-2-binding protein, osteopontin, placental growth factor, growth/differentiation factor 15 and hepatocyte growth factor. All molecules have been suggested to have potential to complement or substitute methods currently used to stage liver diseases. Here, we review the pros and cons for their use in this setting.
\end{abstract}

Citation of this article: Bellan M, Castello LM, Pirisi M. Candidate biomarkers of liver fibrosis: A concise, pathophysiologyoriented review. J Clin Transl Hepatol 2018;6(3):317-325. doi: 10.14218/JCTH.2018.00006.

\section{Introduction}

Hepatic fibrosis is the overly exuberant accumulation of extracellular matrix proteins, including collagen, typically

Keywords: Liver fibrosis; Staging; Biomarkers; Gas6; HGF; PIGF.

Abbreviations: APRI, aspartate aminotransferase-to-platelet ratio; AUC, area under the curve; BEC, biliary epithelial cell; c-Met, tyrosine protein kinase Met; GAS6, growth arrest-specific 6; GDF15, growth differentiation factor 15; HBV, hepatitis B virus; $\mathrm{HCC}$, hepatocellular carcinoma; HCV, hepatitis $\mathrm{C}$ virus; $\mathrm{HGF}$, hepatocyte growth factor; HSC, hepatic stellate cell; HVPG, hepatic venous pressure gradient; KO, knock-out; M2BP, mac-2 binding protein; MFB, myofibroblastic cell; NAFLD, nonalcoholic fatty liver disease; OC, oval cell; OPN, osteopontin; PIGF, placental growth factor; WFA ${ }^{+}$-M2BP, Wisteria floribunda agglutinin-positive Mac-2 binding protein. Received: 24 January 2018; Revised: 25 April 2018; Accepted: 3 May 2018

*Correspondence to: Mattia Bellan, Department of Translational Medicine, Università del Piemonte Orientale UPO, via Solaroli 17, Novara (NO) 28100, Italy. Tel: +39-321-3733966, Fax: +39-321-3733361, E-mail: bellanmattia@yahoo.it triggered by chronic injury of the liver parenchyma with an inflammatory component. This process, analogous to wound healing, may disrupt the hepatic architecture and results in hepatocellular dysfunction and portal hypertension, two of the main features of cirrhosis. ${ }^{1,2}$ Indeed, to the multiplicity of factors (viral, toxic, genetic, nutritional, etc.) causing liver diseases, the counterpart is a relative monotony of pathological features, including degeneration and necrosis of hepatocytes, replacement of liver parenchyma by fibrotic tissue and regenerative nodules and loss of liver function. These events are in fact the result of the activation of common pro-inflammatory and pro-fibrotic pathways. ${ }^{3-5}$

Accurately defining the fibrosis stage reached by a patient along the course of his/her disease is of quintessential clinical importance, since crucial decisions, such as starting monitoring for complications (i.e. esophageal varices or hepatocellular carcinoma (HCC)), depend on it. Unfortunately, the medical history and physical examination do not always provide reliable clues for the detection of advanced fibrosis, since the classical signs of liver diseases are commonly absent or subtle in early cirrhosis. ${ }^{6,7}$ The gold standard for fibrosis detection and quantification is liver biopsy, a procedure poorly accepted by patients, who perceive it as unduly aggressive and risky. ${ }^{8}$ In the past decade, several methods to stage chronic liver disease noninvasively have been proposed or are under evaluation/validation. They fall into the following two broad categories: a) imaging techniques, and b) serum markers, sometimes combined into artificial intelligence algorithms. $^{9}$

Though the noninvasive alternatives have largely replaced liver biopsy for many indications, they also have pitfalls. Ultrasonography, for example, can suggest the presence of fibrosis and cirrhosis but it is neither sensitive nor specific in doing it, performing significantly better only in late stages of liver cirrhosis, when the signs of portal hypertension develop. ${ }^{10}$ Computed tomography and magnetic resonance are more sensitive and specific, but they are also burdened by high costs and inadequate inter-rater reliability among different radiologists; moreover, the extensive use of computed tomography scan is limited by radiological risks. ${ }^{11}$ Finally, transient elastography, besides requiring expensive equipment, maybe inaccurate in obese patients and may lead to over-estimation of fibrosis in patients with high necroinflammatory activity. ${ }^{12}$ Being the result of the sum of inflammation and fibrosis in the liver parenchyma, liver stiffness per se may not be the ideal candidate to monitor for fibrosis regression. 
The ability of the liver to either produce or modify hundreds of chemicals has long been exploited to estimate, from the changes in their blood concentration, the degree to which liver function is impaired and/or organ damage is extensive. Indeed, liver biochemistry panels are included in almost all laboratory routines, being informative, relatively cheap and prone to repeat testing. Conceptually, fibrosis makes no exception. By-products spilling in the blood as a result of the deposition of excess extracellular matrix can be taken as a proxy measure of what is occurring in the liver parenchyma.

Alternatively, patients can be profiled based on artificial intelligence algorithms that produce scores by combining different parameters, including demographics and blood cell counts, such as the aspartate aminotransferase-to-platelet ratio (APRI), ${ }^{13}$ fibrosis- $4^{14}$ or Fibro index. ${ }^{15}$ Unfortunately, neither the former nor the latter approach have produced highly accurate results for liver fibrosis assessment to date, ${ }^{16}$ and their use in clinical practice is not comparable to that of prognostic scores, such as the Child-Pugh-Turcotte classification system ${ }^{17}$ and the Model for End-stage Liver Disease score. ${ }^{18}$ In this context, we also need to account for some derived scores, such as FibroMeter ${ }^{19}$ and FibroTest, ${ }^{20}$ which include more specific blood tests that are not routinely available. Again, the lines of evidence about their reliability and cost-effectiveness are not enough to support their use in clinical practice.

There is always room for improvement. Recently, for example, the use of nt-pro-brain natriuretic peptide and copeptin, prognostic biomarkers in patients with heart failure, ${ }^{21,22}$ has been extended to liver cirrhosis; ${ }^{23,24}$ their concentrations in blood bear a strict relationship to the hemodynamic changes that parallel the progression of liver disease. With putative treatments for liver fibrosis appearing on the horizon, the race to discover the holy grail of a liquid biopsy able to monitor its progression and regression is on. In the present paper we will review current lines of evidence supporting the use of some of the less known but still promising novel biomarkers for the detection of fibrosis in patients with chronic liver diseases.

\section{Growth arrest-specific 6 (Gas6)}

Gas6 is the circulating ligand of three different tyrosine kinase receptors, collectively named TAM, an acronym for Tyro3, AxI and MerTK. The human gene was cloned in 1993 and encodes for a vitamin $\mathrm{K}$-dependent protein which is expressed in different tissues, such as the gut, bone marrow, endothelial cells and fibroblasts. ${ }^{25-27}$ The Gas6/TAM system is highly pleiotropic and has many biological functions. Gas 6 and TAM regulate cell growth and they have been claimed as potential actors in oncogenesis. ${ }^{28}$ Moreover, Gas6 and TAM are implied in the activity of the immune system. MerTK and Axl have been isolated from circulating monocytes and tissue macrophages, ${ }^{29,30}$ and their activation by Gas 6 down-regulates the expression of pro-inflammatory cytokines. ${ }^{31}$ Furthermore, this system is directly involved in the clearance of apoptotic bodies. In fact, Gas6 recognizes phosphatidylserine, a lipid normally expressed on the inner face of the plasma membrane and exposed on the external membrane during apoptosis; by doing it, Gas6 bridges this lipid with TAM receptors, driving macrophages to the recognition of apoptotic cells and to their subsequent phagocytosis. ${ }^{32}$
It is, therefore, not surprising that a dysfunction of this system has been linked to the development of autoimmune and degenerative diseases, since an impaired clearance of apoptotic bodies and an inappropriate inflammatory response are considered critical for the deranged immune response observed in these conditions. On these premises, Gas6 and TAM have been found to be related to rheumatoid arthritis, ${ }^{33}$ connective tissue diseases, ${ }^{34,35}$ Alzheimer's disease ${ }^{36}$ and multiple sclerosis. ${ }^{37}$ Furthermore, TAM are involved in hemostasis, also being receptors of protein $\mathrm{S}$, a master regulator of the coagulative cascade; Gas6 seems to play a complementary role in platelet function ${ }^{38}$ and it has been proposed as a biomarker for the diagnosis of pulmonary embolism. ${ }^{39}$

More recently, the Gas6/TAM interaction has been described to be relevant in inflammatory and repair processes of the liver; in fact, Gas6 seems to play a protective role in response to liver injury. After an acute or chronic injury, repair involves macrophages and hepatic stellate cells (HSCs) activated into myofibroblastic cells (HSCs/MFBs), which produce cytokines and matrix proteins. It has been shown in animal models that Gas6 expression by macrophages, HSCs and HSCs/MFBs is significantly up-regulated in injured areas. In this context, Gas6 exerts an anti-apoptotic effect on both HSCs and HSCs/MFBs, acting as a survival factor for these cells, probably supporting transient HSC/MFB accumulation during liver healing. ${ }^{40}$

Consistent with this finding, in $\mathrm{Gas}^{-/-}$knock-out (KO) mice, a defective wound healing after carbon tetrachlorideinduced liver damage has been reported, with reduced Kupffer cell activation and decreased macrophage and $\mathrm{HSC} /$ MFB recruitment in damaged areas. ${ }^{41}$ Similarly, Gas6 $6^{-/-} \mathrm{KO}$ mice are more prone to severe liver damage after ischemia/ reperfusion injury and the administration of recombinant Gas6 has a protective role either in wild-type or in $\mathrm{KO}$ mice. ${ }^{42}$ This protective role is played at the expense of a fibrogenic effect, however. In fact, Gas6-deficient mice also exhibited reduced liver fibrosis as a consequence of defective macrophage recruitment, inflammatory response and HSC/ MFB activation compared with wild-type animals. ${ }^{43}$

Bárcena et al. ${ }^{44}$ recently demonstrated that blockade of the Gas6/AxI pathway down-regulates HSC activation, collagen deposition and liver fibrogenesis, even postulating a potential therapeutic role for Axl inhibition in the prevention of liver fibrosis. In the same paper, the authors firstly observed a correlation between Gas6 plasma concentration and the progression of liver disease in a group of patients affected by alcoholic liver disease and in a group of hepatitis $\mathrm{C}$ virus (HCV)-infected subjects. According to these authors, Gas6 concentrations were significantly higher in patients than in healthy controls and progressively increased from F0/F1 to compensated and finally to decompensated cirrhosis. ${ }^{44}$ However, the activity of Gas6 in this context probably also implies the activation of MerTK, as suggested by the observation that a specific polymorphism of its gene, associated with lower intrahepatic expression of MerTK, is protective against F2-F4 fibrosis in patients with nonalcoholic fatty liver disease (NAFLD). ${ }^{45}$

On these premises our group recently published a paper demonstrating that Gas6 plasma concentration directly correlates with liver stiffness assessed by liver elastography and is higher in patients with higher degrees of fibrosis assessed by liver biopsy. The diagnostic accuracy was comparable to that of liver elastography. ${ }^{46}$ Of note, Gas6 is also able to 
predict one of the most relevant complications of liver cirrhosis, esophageal varices. ${ }^{47}$

\section{Mac-2 binding protein (M2BP)}

Amongst the most promising molecules identified by proteomics as a candidate marker of fibrosis is M2BP. ${ }^{48}$ M2BP is a 90-kDa glycoprotein, able to promote cell adhesion and to bind selectively to several collagen types and fibronectin, as well as to galectin-3 (formerly known as Mac-2). This protein is secreted by different cell types and, interestingly, it oligomerizes in large ring structures. It has been shown that the biological behavior of M2BP is modified by liver disease progression as a consequence of changes in $\mathrm{N}$-glycosylation; on this basis, a specific test has been developed by Japanese investigators using a Wisteria floribunda agglutinin lectin probe which is able to discriminate this altered $\mathrm{N}$-glycans profile of M2BP. Therefore, Wisteria floribunda agglutininpositive Mac-2 binding protein (WFA ${ }^{+}-\mathrm{M} 2 \mathrm{BP}$ ) has been proposed as a unique glycobiomarker associated with progression of liver disease. ${ }^{49}$

Since its development, this test has been evaluated in many cohorts of patients with chronic liver diseases of different etiologies. Serum level of WFA ${ }^{+}-$M2BP has been validated as a marker of liver fibrosis in $\mathrm{HCV}^{50,51}$ and hepatitis $\mathrm{B}$ virus $(\mathrm{HBV})^{52}$ infected subjects, in NAFLD, ${ }^{53}$ in primary biliary cirrhosis, $^{54}$ and in autoimmune hepatitis. ${ }^{55}$ Moreover, serum levels of WFA ${ }^{+}-$M2BP are predictive of the development of $\mathrm{HCC}$ in patients affected by chronic HCV-related liver disease. In fact, in $\mathrm{HCV}$ infected subjects, the 10 -year cumulative risk of HCC rises from $1.1 \%$ to $54.1 \%$ for different, increasing thresholds of WFA ${ }^{+}-$M2BP plasma concentrations. ${ }^{56}$ Similarly, WFA ${ }^{+}$M2BP plasma concentration was an independent risk factor for HCC in a retrospective cohort of 1323 patients affected by chronic HBV-related liver disease. Along a median follow-up period of 60.3 months, 52 (3.9\%) patients developed HCC. In multivariate analysis, WFA ${ }^{+}-$M2BP predicted HCC development with an adjusted hazard ratio of 1.143 (95\% confidence interval: $1.139-1.829)$, together with male sex and diabetes. Interestingly, the predictive value of $\mathrm{WFA}^{+}-\mathrm{M} 2 \mathrm{BP}$ is even higher in patients without cirrhosis. These findings suggest a potential role for $\mathrm{WFA}^{+}-\mathrm{M} 2 \mathrm{BP}$ in the surveillance strategies for HCC development in the clinical course of chronic liver diseases. 57

Although growing evidence links M2BP to liver fibrosis, it is still not clear whether the increase of its plasma concentration is a simple epiphenomenon or if this molecule plays a pathogenetic role. Recently, an increasing proportion of

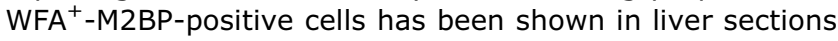
for increasing degrees of fibrosis. According to recent lines of evidence, HSCs are the main cell type responsible for WFA ${ }^{+}-$ M2BP secretion, and probably the interaction of M2BP with Mac-2 expressing Kupffer cells possibly contributing to $\alpha$-smooth muscle actin expression. ${ }^{58}$

However, M2BP is not a disease-specific marker. First of all, it seems to mark fibrotic processes in general. Increased WFA $^{+}-\mathrm{M} 2 \mathrm{BP}$ plasma concentrations have been described in idiopathic pulmonary fibrosis and in chronic pancreatitis. ${ }^{59,60}$ Finally, M2BP probably has a role in cell transformation and cancer spreading. Therefore, many authors have investigated M2BP concentrations in different neoplastic conditions. A role for this biomarker has been postulated and proved for lung, ${ }^{61,62}$ prostate, ${ }^{63,64}$ pancreatic, ${ }^{65}$ gastric $^{66}$ and colorectal cancer. ${ }^{67}$

\section{Osteopontin (OPN)}

OPN is a $32-k D a$ secreted, extracellular matrix glycosylated phosphoprotein, encoded by a gene located on chromosome 4 (4q13). OPN is characterized by a wide conformational flexibility due to extensive posttranslational modification and leading to heterogeneity in phosphorylation, glycosylation and sulphation; ${ }^{68}$ this feature confers OPN different functions, depending on the microenvironment in which it acts. As a pleotropic cytokine, OPN is involved in different physiological and pathological processes, including inflammation, ${ }^{69}$ cancer progression ${ }^{69,70}$ and wound healing. ${ }^{71}$ Many data in the literature confirm OPN as a major determinant of liver fibrosis, both in animal models and in humans, regardless to the cause of liver damage..$^{72}$

In 2012, Urtasun et al. ${ }^{73}$ demonstrated that mice overexpressing the OPN gene develop liver fibrosis spontaneously; these Authors found that the effect is mediated by $\mathrm{PI} 3 \mathrm{~K} / \mathrm{pAkt} / \mathrm{NF}-\kappa \mathrm{B}$ activation which follows the interaction between OPN and $\alpha_{v} \beta_{3}$ integrin on the HSC surface, with consequent collagen-I up-regulation and fibrosis formation. ${ }^{73}$ OPN also plays an important role in fibrillar collagen deposition at periportal spaces, mediated through the activation of oval cells (OCs).OPN prompts OCs to differentiate into biliary epithelial cells (BECs) and causes an inflammatory response, called ductular reaction, which involves BECs and inflammatory cells in the portal tract interface. The ductular reaction is characterized by the production of different molecules that sustain portal fibrosis via the activation of extracellular matrix, HSCs and portal fibroblasts.

Wang et al. ${ }^{74}$ studied the role of OPN in fibrogenesis using two murine models of chronic liver injury, based on chronic thioacetamide administration and common bile duct ligation both in wild-type and OPN null mice. The results pointed out that OPN is a major determinant of the dysregulated response to liver injury that leads to liver fibrosis. The Authors discovered that $\mathrm{OPN}^{-/-}$mice develop less OC and BEC proliferation, less ductular reaction and less collagen-I deposition with respect to wild-type mice. In vitro experiments confirmed the ability of OPN for increasing OC and BEC proliferation. In summary, these findings indicate that OPN, via its interaction with extracellular matrix and adhesion molecules, is an important activator of different cell populations and of the matrix leading to OC proliferation, ductular reaction and fibrogenesis. In this scenario, activated HSCs seem to exert a positive feedback on ductular reaction, inducing a vicious circle in which OPN is involved with a pivotal role. The Authors' hypothesis is that OPN may be one of the major mediators inducing an inflammatory milieu that guides OC proliferation and differentiation, collagen-I up-regulation and TGF- $B$ over-expression. ${ }^{74} \mathrm{~A}$ recent study confirmed this hypothesis and identified the high-mobility group box-1, a chromosomal protein involved in DNA replication, as the mediator of the OPN induced collagen-I up-regulation. ${ }^{75}$

These preclinical studies support the use of OPN as a biomarker of fibrosis, of portal hypertension and of adverse outcome in patients affected by chronic liver disease. Several clinical studies confirmed this hypothesis and suggested the use of OPN as a biomarker of liver fibrosis in HBV chronic infection, ${ }^{76} \mathrm{HCV}$ chronic infection ${ }^{77}$ and in alcohol-induced liver disease. ${ }^{78} \mathrm{~A}$ strong correlation between OPN plasma concentration and the degree of fibrosis, evaluated by liver biopsy, was found by Matsue et al. ${ }^{79}$ in a population of 115 HCV infected patients; they divided their patients into five 
groups according to the histological degree of fibrosis (F0, F1, F2, F3 and F4) and evaluated serum concentrations of different biomarkers (platelet count, and OPN, hyaluronic acid and collagen IV concentrations) and computed scores as APRI and Fibro-Test. In this study, OPN presented as the best diagnostic marker for fibrosis; its plasma concentration, in fact, was significantly different in all the comparisons between groups and the receiver operating characteristic curves allowed for identification of OPN cut-offs able to distinguish F1 versus F2/F3/ F4 patients (OPN: $83 \mathrm{ng} / \mathrm{mL}$; area under the curve (AUC): $0.997), F 1 / F 2$ versus F3/F4 patients (OPN: $124 \mathrm{ng} / \mathrm{mL}$; AUC: 0.999 ) and $F 1 / F 2 / F 3$ versus $F 4$ patients (OPN: $152 \mathrm{ng} / \mathrm{mL}$; AUC: 0.945$)$. None of the other parameters considered gave similar results and the Authors concluded that OPN is an independent predictor of the extent of liver fibrosis in HCV patients and could be used as a non-invasive biomarker to assess the grade of fibrosis in HCV patients. Its use could help to reduce the number of liver biopsies. ${ }^{79}$

Other studies evaluated the relationship between OPN and the presence of complications of cirrhosis, as portal hypertension. In 2016, for example, a study involving 154 cirrhotic patients, mainly affected by alcoholic cirrhosis, demonstrated a relationship between OPN plasma concentration and the hepatic venous pressure gradient (HVPG) measured with the classic wedge technique. The Authors found that OPN plasma concentration was significantly increased in cirrhotic patients with respect to controls (107 vs. $55 \mathrm{ng} / \mathrm{mL}$ respectively). Within cirrhotics, OPN plasma concentration showed a statistically significant correlation with HVPG upon linear regression analysis. A cut-off value of OPN set at $80 \mathrm{ng} / \mathrm{mL}$ showed a sensitivity of $75 \%$ and a specificity of $63 \%$ in identifying patients with a HVPG of $>10 \mathrm{mmHg}$ (AUC: 0.763 ). Setting the OPN cut-off at $90 \mathrm{ng} / \mathrm{mL}$, the data allowed for identification of patients at high risk for variceal bleeding (i.e. patients with HVPG $>12 \mathrm{mmHg}$ ) with a sensitivity of $71 \%$ and a specificity of $62 \%$ (AUC: 0.72 ). These Authors also evaluated the prognostic value of OPN, with a mean follow-up time of 3.7 \pm 2.6 years. Kaplan-Meier curves analysis showed a significantly superior cumulative probability of survival in patients with OPN $<80 \mathrm{ng} / \mathrm{dL}$ with respect to patients with OPN above this cut-off value ( $56 \%$ vs. $37 \%$ respectively with an odds ratio of 2.23). The same trend was confirmed upon stratifying of patients using HVPG (above or below $10 \mathrm{mmHg}$; odds ratio: 2.92 ).

Overall, these data demonstrate the direct involvement of OPN in the scarring process affecting the liver and the strong correlation between the OPN plasma concentration and the liver fibrosis progression. Other recent studies have pointed out the role of OPN in the development and progression of HCC. ${ }^{80}$

In conclusion, OPN seems to be a reliable biomarker for the noninvasive staging of liver fibrosis in different chronic liver diseases; moreover, since many lines of evidence support its important role in the pathophysiology of fibrosis, it is tempting to speculate in favor of a possible role for the OPN/collagen-I axis as a target for future antifibrotic therapies.

\section{Placental growth factor (PIGF)}

PIGF is a member of the vascular endothelial growth factor family, discovered and cloned in the early ' $90 \mathrm{~s}^{81}$ PIGF acts as a pro-angiogenic factor, enhancing the proliferation, migration and survival of endothelial cells. Moreover, it stimulates proliferation of mesenchymal fibroblasts and regulates the contractile response of mural cells, organized around the endothelium. Finally, PIGF activates and attracts macrophages, which in turn release angiogenic and lymphangiogenic factors and interferes with dendritic cell differentiation and accumulation, as well as with antigen recognition. PIGF and its pathway have been claimed as potentially relevant in many different human diseases. One of the most promising applications is chronic liver disease. ${ }^{82}$ The first paper linking PIGF to liver fibrosis was published in 2005, when SalcedoMora et al. ${ }^{83}$ reported an increased PIGF plasma concentration in patients with HCV-related chronic liver disease with respect to healthy controls. More recently, the threshold of $20.2 \mathrm{pg} / \mathrm{mL}$ was reported to be $79 \%$ sensitive and $63 \%$ specific for liver fibrosis $\geq F 2 .{ }^{84}$

Interestingly, PIGF blockade does not affect the healthy vasculature, thus limiting potential adverse reactions. ${ }^{85}$ Van Steenkiste et al. ${ }^{86}$ in 2011 , reported a significant reduction in angiogenesis, arteriogenesis, inflammation, fibrosis, and portal hypertension in cirrhotic PIGF KO mice compared to wild-type mice; similar results were obtained by pharmacologically inhibiting PIGF. ${ }^{86}$ These findings have been recently confirmed; PIGF expression by HSCs is up-regulated in the carbon tetrachloride-induced rodent model of liver cirrhosis, as well as in cirrhotic patients. The knock-down of PIGF attenuates liver fibrosis. In fact, while 8 weeks after the carbon tetrachloride challenge of wild-type mice led to a remarkable extent of fibrosis, PIGF KO mice exhibited thinner septa, mild portal or pericellular fibrosis of the liver, and more preserved hepatic parenchyma. This was paralleled by a reduction in angiogenesis and in HSC proliferation and activation. ${ }^{87}$ On this basis, PIGF blockade has been postulated as a potentially promising therapeutic target for the treatment of chronic liver diseases. ${ }^{88}$

\section{Growth differentiation factor 15 (GDF15)}

GDF15 is a member of the TGF- $\beta$ cytokine superfamily, cloned in 1997 and also known by the name of macrophage inhibitory cytokine $1 .^{89}$ Its gene is located on chromosome 19p12-13.1 and codifies for a 40-kDa propeptide, cleaved in the endoplasmic reticulum to release a $25-\mathrm{kDa}$ active circulating dimeric protein. ${ }^{90}$ Proinflammatory cytokines (i.e. TNF $\alpha$ or interleukin-6) induce GDF15mRNA expression in activated macrophages, which suggests that GDF15 could act as an autocrine inhibitor during the inflammatory response. Probably, the suppression of proinflammatory cytokines plays a role in the induction of immunotolerance towards the fetus; in fact, GDF15 is expressed by the placenta in large amounts under physiological conditions, with increasing concentrations as pregnancy progresses. ${ }^{91}$ Moreover, low serum levels of GDF15 between the 6th and 13th week of gestation may predict miscarriage. ${ }^{92}$

Beside this postulated physiological activity, GDF15 induction has been observed in different pathological conditions, its gene being over-expressed in response to diverse cellular stress signals, such as hypoxia/anoxia, inflammation, acute tissue injuries, and development of neoplasia. On these bases, it has been studied as a biomarker for different diseases. The greatest amount of evidence links GDF15 to cardiovascular diseases and cancer. In fact, higher GDF15 plasma concentrations have been associated to a poor prognosis in myocardial infarction, pulmonary thromboembolism 
and chronic heart failure but it has also been related to cancer invasiveness, metastases and prognosis. ${ }^{93}$

In the last few years, several observations have hinted at a potential role of this growth factor in chronic liver disease. First of all, GDF15 expression in vitro in hepatoma cells is dramatically enhanced by HCV infection, both at the mRNA and the protein level. Moreover, higher GDF15 plasma concentrations are observed in patients affected by HCV and HBV with respect to that in healthy controls. ${ }^{94}$ Considering what is known about GDF15 physiology, this finding probably testifies a response to the stress induced by viral infection and to the consequent liver inflammation. As a further clue, an increase in GDF15 expression has also been reported in mice subjected to bile duct injury. ${ }^{95} \mathrm{~A}$ recent paper smartly elucidated the role of GDF15 in liver pathology using animal models. GDF15 is exclusively expressed by hepatocytes and not by HSCs or by liver-resident macrophages. When hepatocytes are stressed by different stimuli, i.e. alcohol or carbon tetrachloride, the expression of GDF15 gene is enhanced.

Despite being synthesized only by hepatocytes, GDF15 also has effects on HSCs and Kupffer cells. In fact, recombinant GDF15 significantly decreases the lipopolysaccharideinduced pro-inflammatory cytokines production by Kupffer cells. Moreover, when Kupffer cells are co-cultured with GDF15 $\mathrm{KO}$ hepatocytes, the lipopolysaccharide-induced proinflammatory signature is significantly enhanced with respect to co-culture with wild-type hepatocytes. This suggests an important paracrine activity for GDF15. Finally, GDF15 deficiency in GDF15 KO mice enhances alcohol and carbon tetrachloride-induced liver damage and fibrosis. ${ }^{96}$ Taken together, these findings support the hypothesis that different insults to liver parenchyma lead to the increase of GDF15 expression and, consequently, enhance its plasma levels; as such, GDF15 would play a hepato-protective role. This makes GDF15 potentially promising as a diagnostic biomarker of liver damage.

Nonetheless, although raised in cases of viral hepatitis, GDF15 plasma concentration is a stronger marker of advanced liver disease. In fact, in a study by Liu et al., ${ }^{97}$ GDF15 was significantly increased in HBV and HCV infected subjects with respect to healthy controls, but the plasma concentrations were 3 to 6 times higher in patients affected by liver cirrhosis and HCC. Similarly, GDF15 is increased in cases of alcoholic liver cirrhosis ${ }^{98}$ and in patients with advanced, biopsyproven, liver fibrosis in NAFLD. ${ }^{99}$

To the best of our knowledge, GDF15 has been tested as diagnostic biomarker in two different studies. Lee et al. ${ }^{100}$ have demonstrated that GDF15 is able to predict chronic hepatitis, compensated liver cirrhosis and decompensated liver cirrhosis, with an increasing degree of diagnostic accuracy. More interestingly for the purpose of the present review, in a European cohort of 834 patients, GDF15 was $94 \%$ sensitive and $67 \%$ specific for the detection of a significant liver fibrosis ( $\geq \mathrm{F} 2$, assessed by liver biopsy). ${ }^{84}$

\section{Hepatocyte growth factor (HGF)}

HGF is secreted by mesenchymal cells and cleaved by extracellular proteases into a heterodimer composed by a $69-\mathrm{kDa} \alpha$ chain and 34-kDa $\beta$ chain. ${ }^{101}$ Its receptor, tyrosineprotein kinase Met (c-MET), is a class IV receptor tyrosine kinase implicated in many physiological and pathological conditions. C-MET is present on the surface of epithelial cells of multiple organs including liver, pancreas, prostate, kidney, lung and bronchus. ${ }^{102}$ Consequently, although originally identified and cloned as a potent mitogen for hepatocytes, HGF is a strong protective and trophic factor for many tissues and organs. For example, HGF plays a direct role in the proliferation and differentiation of erythroid progenitors. ${ }^{103}$ Moreover, HGF has a crucial role in wound healing and tissue repair, being for example a protective, antifibrotic agent for lung, ${ }^{104}$ kidney $^{105,106}$ and heart ${ }^{107}$ as well.

On the other hand, over-activation of the HGF/c-MET pathway has been shown in the pathogenesis and in the prognosis of many different neoplastic conditions. C-MET is a proto-oncogene, since an altered form, causing constitutive kinase activity, has been cloned as a transforming factor from a chemically-induced human osteosarcoma cell line. ${ }^{108}$ Furthermore, a germline mutation of c-MET has been identified as the cause of familial cases of hereditary papillary renal cell carcinomas. ${ }^{109}$ Finally, c-MET over-expression is associated with a poor prognosis in many human tumors, such as colorectal, ovarian and breast cancers. ${ }^{110}$

With regard to liver physiology and pathology, HGF is an important hepato-protective and pro-regenerative factor during liver injuries. The main intrahepatic source of HGF is Kupffer cells; local pro-inflammatory cytokines expressed as a consequence of liver damage are responsible for HGF gene up-regulation. ${ }^{111}$ According to many pre-clinical data, HGF is a promising therapeutic tool for liver diseases. In fact, different experiments have been performed, including gene therapy, transfection of mesenchymal cells over-expressing HGF and the use of recombinant HGF. Independently from the strategy adopted, HGF was able to suppress the development of liver cirrhosis after toxic damage in experimental rats $^{112,113}$ and cholestatic damage, ${ }^{114}$ to prevent liver failure ${ }^{115}$ and, in contrast to its anti-apoptotic activity on hepatocytes, to exert an inhibitory and pro-apoptotic effect on HCC cells. ${ }^{116}$

As occurs for other hepato-protective molecules, the local production of HGF is increased during chronic liver disease, paralleling its increase in plasma concentration. Higher blood concentrations of HGF have been found in cirrhotic patients compared to controls and alcoholics without liver cirrhosis. Moreover, significantly higher concentrations of HGF have been observed in patients with Child class $C$ liver cirrhosis compared to patients with Child class A liver cirrhosis. ${ }^{117}$ Furthermore, HGF plasma concentrations are able to effectively distinguish liver cirrhosis from mild fibrosis in HCV infected subjects. ${ }^{118}$ On these bases, HGF has been postulated as a promising biomarker of liver fibrosis. According to a recent study, HGF performs well as a biomarker of chronic liver disease progression. In fact, it showed a $97 \%$ sensitivity and a $64 \%$ specificity in the detection of a histological F2 or higher stage of liver fibrosis. ${ }^{84}$

However, it should be noted that HGF is not hepato-specific and its plasma concentration is increased in different pathological conditions. ${ }^{119-121}$

\section{Conclusions}

The staging of liver fibrosis is of great importance in the management of chronic liver diseases, but it is made difficult by the inaccuracy of the methods currently available. This is why the search for circulating biomarkers is clinically relevant. Moreover, chronic liver diseases, though multifactorial, share common pathways leading to fibrosis and cirrhosis, which are still largely unknown. The discovery of novel 
Bellan M. et al: Novel biomarkers of liver fibrosis

Table 1. Diagnostic value of candidate biomarkers of liver fibrosis

\begin{tabular}{|c|c|c|c|c|c|c|c|c|}
\hline & Value & Sens & Spec & $\begin{array}{l}\text { Predictive } \\
\text { value }\end{array}$ & AUC & $\begin{array}{l}\text { Publication, } \\
\text { yearRef }\end{array}$ & Etiology & $\begin{array}{l}\text { Definition of } \\
\text { fibrosis }\end{array}$ \\
\hline \multirow[t]{2}{*}{ Gas6 } & $30 \mathrm{ng} / \mathrm{mL}$ & $84 \%$ & $56 \%$ & N/A & 0.734 & $\begin{array}{l}\text { Bellan et al. } \\
2016^{46}\end{array}$ & $\begin{array}{l}\text { Mixed, 92\% } \\
\text { viral }\end{array}$ & Ishak $\leq 1$ \\
\hline & $42 \mathrm{ng} / \mathrm{mL}$ & $64 \%$ & $95 \%$ & N/A & 0.788 & $\begin{array}{l}\text { Bellan et al. } \\
2016^{46}\end{array}$ & & Ishak $\geq 4$ \\
\hline \multirow[t]{6}{*}{ M2BP } & 2.21 C.O.I. & $88.2 \%$ & $78.7 \%$ & $\begin{array}{l}\text { PPV } 58.9 \% \\
\text { NPV } 94.5 \%\end{array}$ & 0.812 & $\begin{array}{l}\text { Toshima et al. } \\
2015^{50}\end{array}$ & $\mathrm{HCV}$ & Metavir $\geq 3$ \\
\hline & 1.00 C.O.I. & $67 \%$ & $70 \%$ & $\begin{array}{l}\text { PPV } 53 \% \\
\text { NPV } 81 \%\end{array}$ & 0.680 & $\begin{array}{l}\text { Nakamura et al. } \\
2017^{52}\end{array}$ & HBV & Ishak $\geq 3$ \\
\hline & 2.00 C.O.I. & $69 \%$ & $74 \%$ & $\begin{array}{l}\text { PPV } 57 \% \\
\text { NPV } 83 \%\end{array}$ & 0.795 & $\begin{array}{l}\text { Nakamura et al. } \\
2017^{52}\end{array}$ & $\mathrm{HCV}$ & Ishak $\geq 3$ \\
\hline & 1.57 C.O.I. & $85.9 \%$ & $74.6 \%$ & N/A & 0.879 & Abe et al. $2015^{53}$ & NAFLD & Metavir $\geq 3$ \\
\hline & 1.40 C.O.I. & $83 \%$ & $90 \%$ & $\begin{array}{l}\text { PPV 69\%, } \\
\text { NPV 95\% }\end{array}$ & 0.933 & $\begin{array}{l}\text { Umemura et al. } \\
2015^{54}\end{array}$ & PBC & Metavir $\geq 3$ \\
\hline & 3.70 C.O.I. & $64.3 \%$ & $83.3 \%$ & N/A & 0.747 & $\begin{array}{l}\text { Nishikawa et al. } \\
2016^{55}\end{array}$ & $\begin{array}{l}\text { Autoimmune } \\
\text { hepatitis }\end{array}$ & Metavir $\geq 3$ \\
\hline \multirow[t]{2}{*}{ OPN } & $2.9 \mathrm{ng} / \mathrm{mL}$ & $96.4 \%$ & $94.1 \%$ & N/A & 0.957 & $\begin{array}{l}\text { Huang et al. } \\
2010^{77}\end{array}$ & $\mathrm{HCV}$ & Metavir $\geq 3$ \\
\hline & $124 \mathrm{ng} / \mathrm{mL}$ & $97.1 \%$ & $100 \%$ & N/A & 0.997 & $\begin{array}{l}\text { Matsue et al. } \\
2015^{79}\end{array}$ & $\mathrm{HCV}$ & Metavir $\geq 3$ \\
\hline \multirow[t]{2}{*}{ PIGF } & $20.2 \mathrm{pg} / \mathrm{mL}$ & $79 \%$ & $63 \%$ & N/A & 0.758 & $\begin{array}{l}\text { Krawczyk et al. } \\
2017^{84}\end{array}$ & Mixed & $\begin{array}{l}\text { Desmet } \\
\text { Scheuer } \geq 2\end{array}$ \\
\hline & $21.9 \mathrm{pg} / \mathrm{mL}$ & N/A & N/A & N/A & 0.771 & $\begin{array}{l}\text { Krawczyk et al. } \\
2017^{84}\end{array}$ & Mixed & $\begin{array}{l}\text { Desmet } \\
\text { Scheuer } \geq 3\end{array}$ \\
\hline \multirow[t]{2}{*}{ GDF15 } & $1582.8 \mathrm{pg} / \mathrm{mL}$ & $94 \%$ & $67 \%$ & N/A & 0.854 & $\begin{array}{l}\text { Krawczyk et al. } \\
2017^{84}\end{array}$ & Mixed & $\begin{array}{l}\text { Desmet } \\
\text { Scheuer } \geq 2\end{array}$ \\
\hline & $1563.7 \mathrm{pg} / \mathrm{mL}$ & N/A & N/A & N/A & 0.901 & $\begin{array}{l}\text { Krawczyk et al. } \\
2017^{84}\end{array}$ & Mixed & $\begin{array}{l}\text { Desmet } \\
\text { Scheuer } \geq 3\end{array}$ \\
\hline \multirow[t]{2}{*}{ HGF } & $2598 \mathrm{pg} / \mathrm{mL}$ & $97 \%$ & $64 \%$ & N/A & 0.849 & $\begin{array}{l}\text { Krawczyk et al. } \\
2017^{84}\end{array}$ & Mixed & $\begin{array}{l}\text { Desmet } \\
\text { Scheuer } \geq 2\end{array}$ \\
\hline & $2085.7 \mathrm{pg} / \mathrm{mL}$ & N/A & N/A & N/A & 0.888 & $\begin{array}{l}\text { Krawczyk et al. } \\
2017^{84}\end{array}$ & Mixed & $\begin{array}{l}\text { Desmet } \\
\text { Scheuer } \geq 3\end{array}$ \\
\hline
\end{tabular}

Abbreviations: AUC, area under the curve; C.O.I., cut-off index; M2BP, Mac-2 binding protein; GDF15, growth differentiation factor 15; HGF, hepatocyte growth factor; N/A, not available; NPV, negative predictive value; OPN, osteopontin; PIGF, placental growth factor; PPV, positive predictive value; Sens, sensitivity; Spec, specificity.

biomarkers of liver fibrosis is, therefore, not only potentially promising from a clinical point of view but could even contribute to deepening our knowledge about the biological mechanisms underlying the development of liver fibrosis. Finally, the current treatment strategies are essentially based on the removal of the cause, subsiding the fibrotic process; a better knowledge of the mechanisms beyond the development of liver cirrhosis could also give us the opportunity to develop new drugs directly targeting liver fibrosis.

In the last decades, dozens of putative molecules have been proposed to monitor the clinical course of liver diseases. In the present paper we have presented some of the most promising, reviewing their biology and the line of evidence supporting their use in clinical practice. These biomarkers share some common pros and cons. First and foremost, they can be tested easily, safely and inexpensively, overcoming some of the main issues of the methods currently available ( $i$. e. liver biopsy and imaging techniques). These features make them particularly suitable for repeat measurements and, therefore, for monitoring patients during the clinical course of their disease.

However, none of them is organ-specific. Their plasma concentrations are generally increased not only as a consequence of the development of liver fibrosis but also in several other different conditions. Furthermore, hepatic and renal clearance can interfere with circulating plasma levels. On these premises, their routine use in clinical practice cannot be currently supported. Other studies are required in the near future to better validate these biomarkers, the use of which cannot be established without a good selection of patients undergoing tests of the dosages, to lower the number of false positive subjects.

In the present paper we have reviewed the evidence about the use of six different potential biomarkers of liver fibrosis. In Table 1, we compared the diagnostic performance of these molecules. We included those papers in which the diagnostic performance has been analyzed with respect to the gold standard - the liver biopsy. It is evident that the comparison 
between the different markers is difficult because different scoring systems have been used and different etiologies of liver disease have been considered. However, the majority of papers have evaluated the ability of the different molecules to identify severe fibrosis.

Moreover, it is reasonable that these novel biomarkers might find their best use within more complex algorithms rather than in the simple measurement of their plasma concentration. For example, the combined use of PIGF, HGF and GDF15 has been recently tested. The sensitivity and specificity of at least one marker positive for fibrosis stage F2 or higher was $84 \%$ and $72 \%$, respectively, resulting in a positive predictive value of $89 \%$ and a negative predictive value of $63 \%$. Moreover, the use of this approach was effective in identifying $50 \%$ of those patients with a significant degree of fibrosis, who would have been missed by a strategy based only on transient elastography. ${ }^{84}$ Similar future studies will establish which combination of biomarkers will prove to represent a breakthrough for the non-invasive assessment of fibrosis.

\section{Conflict of interest}

The authors have no conflict of interests related to this publication.

\section{Author contributions}

Contributed equally in study design, manuscript drafting and manuscript revision (MB, LMC, MP).

\section{References}

[1] Bataller R, Brenner DA. Liver fibrosis. J Clin Invest 2005;115:209-218. doi: $10.1172 / \mathrm{JCI} 24282$

[2] Friedman SL. Liver fibrosis - from bench to bedside. J Hepatol 2003;38: S38-S53. doi: 10.1016/S0168-8278(02)00429-4.

[3] Zhou WC, Zhang QB, Qiao L. Pathogenesis of liver cirrhosis. World J Gastroenterol 2014;20:7312-7324. doi: 10.3748/wjg.v20.i23.7312.

[4] Wanless IR, Nakashima E, Sherman M. Regression of human cirrhosis. Morphologic features and the genesis of incomplete septal cirrhosis. Arch Pathol Lab Med 2000;124:1599-1607. doi: 10.1043/0003-9985(2000)124<1599: $\mathrm{ROHC}>2.0 . \mathrm{CO} ; 2$

[5] Ferrell L. Liver pathology: cirrhosis, hepatitis, and primary liver tumors. Update and diagnostic problems. Mod Pathol 2000;13:679-704. doi: 10. 1038/modpathol.3880119.

[6] de Bruyn G, Graviss EA. A systematic review of the diagnostic accuracy of physical examination for the detection of cirrhosis. BMC Med Inform Decis Mak 2001;1:6. doi: 10.1186/1472-6947-1-6.

[7] Udell JA, Wang CS, Tinmouth J, FitzGerald JM, Ayas NT, Simel DL, et al. Does this patient with liver disease have cirrhosis? JAMA 2012;307:832-842. doi: 10.1001/jama.2012.186.

[8] EASL Clinical Practice Guidelines: management of hepatitis C virus infection. J Hepatol 2014;60:392-420. doi: 10.1016/j.jhep.2013.11.003.

[9] Tapper EB, Lok AS. Use of liver imaging and biopsy in clinical practice. N Engl J Med 2017;377:756-768. doi: 10.1056/NEJMra1610570.

[10] Allan R, Thoirs K, Phillips M. Accuracy of ultrasound to identify chronic liver disease. World J Gastroenterol 2010;16:3510-3520. doi: 10.3748/wjg. v16.i28.3510.

[11] Venkatesh SK, Yin M, Takahashi N, Glockner JF, Talwalkar JA, Ehman RL. Non-invasive detection of liver fibrosis: MR imaging features vs. MR elastography. Abdom Imaging 2015;40:766-775. doi: 10.1007/s00261015-0347-6.

[12] Arena U, Vizzutti F, Corti G, Ambu S, Stasi C, Bresci S, et al. Acute viral hepatitis increases liver stiffness values measured by transient elastography. Hepatology 2008;47:380-384. doi: 10.1002/hep.22007.

[13] Wai CT, Greenson JK, Fontana RJ, Kalbfleisch JD, Marrero JA, Conjeevaram $\mathrm{HS}$, et al. A simple noninvasive index can predict both significant fibrosis and cirrhosis in patients with chronic hepatitis C. Hepatology 2003;38: 518-526. doi: 10.1053/jhep.2003.50346.
[14] Sterling RK, Lissen E, Clumeck N, Sola R, Correa MC, Montaner J, et al. Development of a simple noninvasive index to predict significant fibrosis in patients with HIV/HCV coinfection. Hepatology 2006;43:1317-1325. doi: $10.1002 /$ hep. 21178.

[15] Koda M, Matunaga Y, Kawakami M, Kishimoto Y, Suou T, Murawaki Y. FibroIndex, a practical index for predicting significant fibrosis in patients with chronic hepatitis C. Hepatology 2007;45:297-306. doi: 10.1002/hep.21520.

[16] Nallagangula KS, Nagaraj SK, Venkataswamy L, Chandrappa M. Liver fibrosis: a compilation on the biomarkers status and their significance during disease progression. Future Sci OA 2017;4:FSO250. doi: 10.4155/fsoa2017-0083.

[17] Child CG, Turcotte JG. Surgery and portal hypertension. In: Child CG, ed. The liver and portal hypertension. Philadelphia: Saunders, 1964:50-64.

[18] Kamath PS, Wiesner RH, Malinchoc M, Kremers W, Therneau TM, Kosberg $\mathrm{CL}$, et al. A model to predict survival in patients with end-stage liver disease. Hepatology 2001;33:464-470. doi: 10.1053/jhep.2001.22172.

[19] Calès P, Boursier J, Oberti F, Hubert I, Gallois Y, Rousselet MC, et al. FibroMeters: a family of blood tests for liver fibrosis. Gastroenterol Clin Biol 2008;32:40-51. doi: 10.1016/S0399-8320(08)73992-7.

[20] Rossi E, Adams L, Prins A, Bulsara M, de Boer B, Garas G, et al. Validation of the FibroTest biochemical markers score in assessing liver fibrosis in hepatitis C patients. Clin Chem 2003;49:450-454. doi: 10.1373/49.3.450.

[21] Vetrone F, Santarelli S, Russo V, Lalle I, De Berardinis B, Magrini L, et al. Copeptin decrease from admission to discharge has favorable prognostic value for 90-day events in patients admitted with dyspnea. Clin Chem Lab Med 2014;52:1457-1464. doi: 10.1515/cclm-2014-0207.

[22] Winther JA, Brynildsen J, Høiseth AD, Strand H, Følling I, Christensen G, et al. Prognostic and diagnostic significance of copeptin in acute exacerbation of chronic obstructive pulmonary disease and acute heart failure: data from the ACE 2 study. Respir Res 2017;18:184. doi: 10.1186/s12931-017-0665-z.

[23] Solà E, Kerbert AJ, Verspaget HW, Moreira R, Pose E, Ruiz P, et al. Plasma copeptin as biomarker of disease progression and prognosis in cirrhosis. J Hepatol 2016;65:914-920. doi: 10.1016/j.jhep.2016.07.003.

[24] Licata A, Corrao S, Petta S, Genco C, Cardillo M, Calvaruso V, et al. NT pro BNP plasma level and atrial volume are linked to the severity of liver cirrhosis. PLoS One 2013;8:e68364. doi: 10.1371/journal.pone.0068364.

[25] Manfioletti G, Brancolini C, Avanzi G, Schneider C. The protein encoded by a growth arrest-specific gene (gas6) is a new member of the vitamin Kdependent proteins related to protein $S$, a negative coregulator in the blood coagulation cascade. Mol Cell Biol 1993;13:4976-4985. doi: 10. 1128/MCB.13.8.4976.

[26] Avanzi GC, Gallicchio M, Cavalloni G, Gammaitoni L, Leone F, Rosina A, et al. GAS6, the ligand of AxI and Rse receptors, is expressed in hematopoietic tissue but lacks mitogenic activity. Exp Hematol 1997;25:1219-1226.

[27] Melaragno MG, Wuthrich DA, Poppa V, Gill D, Lindner V, Berk BC, et al. Increased expression of $A x I$ tyrosine kinase after vascular injury and regulation by $\mathrm{G}$ protein-coupled receptor agonists in rats. Circ Res 1998;83: 697-704. doi: 10.1161/01.RES.83.7.697.

[28] Wu G, Ma Z, Hu W, Wang D, Gong B, Fan C, et al. Molecular insights of Gas6/TAM in cancer development and therapy. Cell Death Dis 2017;8: e2700. doi: 10.1038/cddis.2017.113.

[29] Graham DK, Dawson TL, Mullaney DL, Snodgrass HR, Earp HS. Cloning and mRNA expression analysis of a novel human protooncogene, c-mer. Cell Growth Differ 1994;5:647-657.

[30] Neubauer A, Fiebeler A, Graham DK, O'Bryan JP, Schmidt CA, Barckow P, et al. Expression of axl, a transforming receptor tyrosine kinase, in normal and malignant hematopoiesis. Blood 1994;84:1931-1941.

[31] Alciato F, Sainaghi PP, Sola D, Castello L, Avanzi GC. TNF-alpha, IL-6, and IL1 expression is inhibited by GAS6 in monocytes/macrophages. J Leukoc Biol 2010;87:869-875. doi: 10.1189/jlb.0909610.

[32] Scott RS, McMahon EJ, Pop SM, Reap EA, Caricchio R, Cohen PL, et al. Phagocytosis and clearance of apoptotic cells is mediated by MER. Nature 2001;411:207-211. doi: 10.1038/35075603.

[33] Kurowska-Stolarska M, Alivernini S, Melchor EG, Elmesmari A, Tolusso B, Tange $C$, et al. MicroRNA-34a dependent regulation of AXL controls the activation of dendritic cells in inflammatory arthritis. Nat Commun 2017; 8:15877. doi: $10.1038 /$ ncomms15877.

[34] Jung JY, Suh $\mathrm{CH}$. Incomplete clearance of apoptotic cells in systemic lupus erythematosus: pathogenic role and potential biomarker. Int J Rheum Dis 2015;18:294-303. doi: 10.1111/1756-185X.12568.

[35] Chen CH, Chen HC, Chang CC, Peng YJ, Lee CH, Shieh YS, et al. Growth arrest-specific 6 protein in patients with sjögren syndrome: determination of the plasma level and expression in the labial salivary gland. PLoS One 2015;10:e0139955. doi: 10.1371/journal.pone.0139955.

[36] Sainaghi PP, Bellan M, Lombino F, Alciato F, Carecchio M, Galimberti D, et al. Growth arrest specific 6 concentration is increased in the cerebrospinal fluid of patients with alzheimer's disease. J Alzheimers Dis 2017;55:59-65. doi: 10.3233/JAD-160599.

[37] Bellan M, Pirisi M, Sainaghi PP. The Gas6/TAM system and multiple sclerosis. Int J Mol Sci 2016;17:1807. doi: 10.3390/ijms17111807. 
[38] van der Meer JH, van der Poll T, van 't Veer C. TAM receptors, Gas6, and protein S: roles in inflammation and hemostasis. Blood 2014;123:2460-2469. doi: 10.1182/blood-2013-09-528752.

[39] Sainaghi PP, Alciato F, Carnieletto $S$, Castello L, Bergamasco L, Sola D, et al. Gas6 evaluation in patients with acute dyspnea due to suspected pulmonary embolism. Respir Med 2009;103:589-594. doi: 10.1016/j.rmed.2008.10. 018.

[40] Lafdil F, Chobert MN, Couchie D, Brouillet A, Zafrani ES, Mavier $P$, et al. Induction of Gas 6 protein in $\mathrm{CCl} 4$-induced rat liver injury and anti-apoptotic effect on hepatic stellate cells. Hepatology 2006;44:228-239. doi: 10 . 1002/hep. 21237

[41] Lafdil F, Chobert MN, Deveaux V, Zafrani ES, Mavier $P, N a k a n o ~ T$, et al. Growth arrest-specific protein 6 deficiency impairs liver tissue repair after acute toxic hepatitis in mice. J Hepatol 2009;51:55-66. doi: 10.1016/j.jhep. 2009.02.030

[42] Llacuna L, Bárcena C, Bellido-Martín L, Fernández L, Stefanovic M, Marí M, et al. Growth arrest-specific protein 6 is hepatoprotective against murine ischemia/reperfusion injury. Hepatology 2010;52:1371-1379. doi: 10 . 1002/hep. 23833

[43] Fourcot A, Couchie D, Chobert MN, Zafrani ES, Mavier P, Laperche Y, et al. Gas6 deficiency prevents liver inflammation, steatohepatitis, and fibrosis in mice. Am J Physiol Gastrointest Liver Physiol 2011;300:G1043-G1053. doi: 10.1152/ajpgi.00311.2010.

[44] Bárcena C, Stefanovic M, Tutusaus A, Joannas L, Menéndez A, García-Ruiz C, et al. Gas6/Axl pathway is activated in chronic liver disease and its targeting reduces fibrosis via hepatic stellate cell inactivation. J Hepatol 2015; 63:670-678. doi: 10.1016/j.jhep.2015.04.013.

[45] Petta S, Valenti L, Marra F, Grimaudo S, Tripodo C, Bugianesi E, et al. MERTK rs4374383 polymorphism affects the severity of fibrosis in non-alcoholic fatty liver disease. J Hepatol 2016;64:682-690. doi: 10.1016/j.jhep. 2015.10.016.

[46] Bellan M, Pogliani G, Marconi C, Minisini R, Franzosi L, Alciato F, et al. Gas6 as a putative noninvasive biomarker of hepatic fibrosis. Biomark Med 2016 10:1241-1249. doi: 10.2217/bmm-2016-0210.

[47] Bellan M, Sainaghi PP, Minh MT, Minisini R, Molinari L, Baldrighi M, et al. Gas6 as a predictor of esophageal varices in patients affected by hepatitis $C$ virus related-chronic liver disease. Biomark Med 2018;12:27-34. doi: 10 2217/bmm-2017-0171.

[48] Cheung KJ, Tilleman K, Deforce D, Colle I, Van Vlierberghe H. The HCV serum proteome: a search for fibrosis protein markers. J Viral Hepat 2009;16:418-429. doi: 10.1111/j.1365-2893.2009.01083.x.

[49] Kuno A, Ikehara Y, Tanaka Y, Ito K, Matsuda A, Sekiya S, et al. A serum "sweet-doughnut" protein facilitates fibrosis evaluation and therapy assessment in patients with viral hepatitis. Sci Rep 2013;3:1065. doi: 10. 1038/srep01065.

[50] Toshima T, Shirabe K, Ikegami T, Yoshizumi T, Kuno A, Togayachi A, et al. A novel serum marker, glycosylated Wisteria floribunda agglutinin-positive Mac-2 binding protein (WFA(+)-M2BP), for assessing liver fibrosis. J Gastroenterol 2015;50:76-84. doi: 10.1007/s00535-014-0946-y.

[51] Xu $H$, Kong $W$, Liu L, Chi $X$, Wang $X$, Wu R, et al. Accuracy of M2BPGi, compared with Fibro Scan ${ }^{\circledR}$, in analysis of liver fibrosis in patients with hepatitis C. BMC Gastroenterol 2017;17:62. doi: 10.1186/s12876-0170618-5.

[52] Nakamura $M$, Kanda $T$, Jiang $X$, Haga $Y$, Takahashi $K$, Wu $S$, et al. Serum microRNA-122 and Wisteria floribunda agglutinin-positive Mac-2 binding protein are useful tools for liquid biopsy of the patients with hepatitis $B$ virus and advanced liver fibrosis. PLoS One 2017;12:e0177302. doi: 10. 1371/journal.pone.0177302.

[53] Abe M, Miyake T, Kuno A, Imai Y, Sawai Y, Hino K, et al. Association between Wisteria floribunda agglutinin-positive Mac-2 binding protein and the fibrosis stage of non-alcoholic fatty liver disease. J Gastroenterol 2015;50: 776-784. doi: 10.1007/s00535-014-1007-2.

[54] Umemura T, Joshita S, Sekiguchi T, Usami Y, Shibata S, Kimura T, et al. Serum wisteria floribunda agglutinin-positive Mac-2-binding protein leve predicts liver fibrosis and prognosis in primary biliary cirrhosis. Am J Gastroenterol 2015;110:857-864. doi: 10.1038/ajg.2015.118.

[55] Nishikawa H, Enomoto H, Iwata Y, Hasegawa K, Nakano C, Takata R, et al. Clinical significance of serum Wisteria floribunda agglutinin positive Mac2-binding protein level and high-sensitivity C-reactive protein concentration in autoimmune hepatitis. Hepatol Res 2016;46:613-621. doi: 10.1111/hepr.12596

[56] Yamasaki K, Tateyama M, Abiru S, Komori A, Nagaoka S, Saeki A, et al. Elevated serum levels of Wisteria floribunda agglutinin-positive human Mac-2 binding protein predict the development of hepatocellular carcinoma in hepatitis C patients. Hepatology 2014;60:1563-1570. doi: 10.1002/hep. 27305.

[57] Kim SU, Heo JY, Kim BK, Park JY, Kim DY, Han KH, et al. Wisteria floribunda agglutinin-positive human Mac-2 binding protein predicts the risk of HBVrelated liver cancer development. Liver Int 2017;37:879-887. doi: 10 . 1111/liv.13341.
[58] Bekki $Y$, Yoshizumi $T$, Shimoda $S$, Itoh $S$, Harimoto $N$, Ikegami $T$, et al. Hepatic stellate cells secreting WFA+ -M2BP: Its role in biological interactions with Kupffer cells. J Gastroenterol Hepatol 2017;32:1387-1393. doi: $10.1111 /$ jgh. 13708.

[59] Kono M, Nakamura $Y$, Oyama $Y$, Mori K, Hozumi H, Karayama M, et al. Increased levels of serum Wisteria floribunda agglutinin-positive Mac-2 binding protein in idiopathic pulmonary fibrosis. Respir Med 2016;115: 46-52. doi: 10.1016/j.rmed.2016.04.013.

[60] Fujiyama T, Ito T, Ueda K, Tachibana Y, Yasunaga K, Miki M, et al. Serum levels of Wisteria floribunda agglutinin-positive Mac-2 binding protein reflect the severity of chronic pancreatitis. J Dig Dis 2017;18:302-308. doi: 10.1111/1751-2980.12475.

[61] Ozaki Y, Kontani K, Hanaoka J, Chano T, Teramoto K, Tezuka N, et al. Expression and immunogenicity of a tumor-associated antigen, $90 \mathrm{~K} / \mathrm{Mac}-2$ binding protein, in lung carcinoma. Cancer 2002;95:1954-1962. doi: 10.1002/cncr. 10899.

[62] Marchetti A, Tinari N, Buttitta F, Chella A, Angeletti CA, Sacco R, et al. Expression of $90 \mathrm{~K}$ (Mac-2 BP) correlates with distant metastasis and predicts survival in stage I non-small cell lung cancer patients. Cancer Res 2002;62:2535-2539.

[63] Bair EL, Nagle RB, Ulmer TA, Laferté S, Bowden GT. 90K/Mac-2 binding protein is expressed in prostate cancer and induces promatrilysin expression. Prostate 2006;66:283-293. doi: 10.1002/pros.20343.

[64] Hu J, He J, Kuang $Y$, Wang Z, Sun Z, Zhu H, et al. Expression and significance of 90K/Mac-2BP in prostate cancer. Exp Ther Med 2013;5:181-184. doi: 10.3892/etm.2012.768.

[65] Waragai $Y$, Suzuki $R$, Takagi $T$, Sugimoto $M$, Asama $H$, Watanabe $K$, et al. Clinical significance of serum Wisteria floribunda agglutinin-positive Mac-2 binding protein in pancreatic ductal adenocarcinoma. Pancreatology 2016; 16:1044-1050. doi: 10.1016/j.pan.2016.09.003.

[66] Park YP, Choi SC, Kim JH, Song EY, Kim JW, Yoon DY, et al. Up-regulation of Mac-2 binding protein by hTERT in gastric cancer. Int J Cancer 2007;120: 813-820. doi: 10.1002/ijc.22369.

[67] Wu CC, Huang YS, Lee LY, Liang Y, Tang RP, Chang YS, et al. Overexpression and elevated plasma level of tumor-associated antigen $90 \mathrm{~K} / \mathrm{Mac}-2$ binding protein in colorectal carcinoma. Proteomics Clin Appl 2008;2:1586-1595. doi: 10.1002/prca.200800080.

[68] Kurzbach D, Platzer G, Schwarz TC, Henen MA, Konrat R, Hinderberger D. Cooperative unfolding of compact conformations of the intrinsically disordered protein osteopontin. Biochemistry 2013;52:5167-5175. doi: 10 1021/bi400502c.

[69] Castello LM, Raineri D, Salmi L, Clemente N, Vaschetto R, Quaglia M, et al. Osteopontin at the crossroads of inflammation and tumor progression. Mediators Inflamm 2017;2017:4049098. doi: 10.1155/2017/4049098.

[70] Shi L, Wang X. Role of osteopontin in lung cancer evolution and heterogeneity. Semin Cell Dev Biol 2017;64:40-47. doi: 10.1016/j.semcdb.2016. 08.032.

[71] Lund SA, Giachelli CM, Scatena M. The role of osteopontin in inflammatory processes. J Cell Commun Signal 2009;3:311-322. doi: 10.1007/s12079009-0068-0.

[72] Wen $Y$, Jeong $S$, Xia Q, Kong X. Role of osteopontin in liver diseases. Int J Biol Sci 2016;12:1121-1128. doi: 10.7150/ijbs.16445.

[73] Urtasun R, Lopategi A, George J, Leung TM, Lu Y, Wang X, et al. Osteopontin, an oxidant stress sensitive cytokine, up-regulates collagen-I via integrin $\alpha(V) \beta(3)$ engagement and PI3K/pAkt/NFKB signaling. Hepatology 2012;55: 594-608. doi: 10.1002/hep.24701.

[74] Wang X, Lopategi A, Ge X, Lu Y, Kitamura N, Urtasun R, et al. Osteopontin induces ductular reaction contributing to liver fibrosis. Gut 2014;63: 1805-1818. doi: 10.1136/gutjnl-2013-306373.

[75] Arriazu E, Ge X, Leung TM, Magdaleno F, Lopategi A, Lu Y, et al. Signalling via the osteopontin and high mobility group box-1 axis drives the fibrogenic response to liver injury. Gut 2017;66:1123-1137. doi: 10.1136/gutjnl2015-310752.

[76] Zhao L, Li T, Wang Y, Pan Y, Ning H, Hui X, et al. Elevated plasma osteopontin level is predictive of cirrhosis in patients with hepatitis B infection. Int J Clin Pract 2008;62:1056-1062. doi: 10.1111/j.1742-1241.2007.01368.x.

[77] Huang W, Zhu G, Huang M, Lou G, Liu Y, Wang S. Plasma osteopontin concentration correlates with the severity of hepatic fibrosis and inflammation in HCV-infected subjects. Clin Chim Acta 2010;411:675-678. doi: 10. 1016/j.cca.2010.01.029

[78] Patouraux S, Bonnafous S, Voican CS, Anty R, Saint-Paul MC, RosenthalAllieri MA, et al. The osteopontin level in liver, adipose tissue and serum is correlated with fibrosis in patients with alcoholic liver disease. PLoS One 2012;7:e35612. doi: 10.1371/journal.pone.0035612.

[79] Matsue Y, Tsutsumi M, Hayashi N, Saito T, Tsuchishima M, Toshikuni N, et al. Serum osteopontin predicts degree of hepatic fibrosis and serves as a biomarker in patients with hepatitis C virus infection. PLoS One 2015;10: e0118744. doi: 10.1371/journal.pone.0118744.

[80] Cabiati M, Gaggini M, Cesare MM, Caselli C, De Simone P, Filipponi F, et al. Osteopontin in hepatocellular carcinoma: A possible biomarker for 
diagnosis and follow-up. Cytokine 2017;99:59-65. doi: 10.1016/j.cyto. 2017.07.004.

[81] Maglione D, Guerriero V, Viglietto G, Delli-Bovi P, Persico MG. Isolation of a human placenta cDNA coding for a protein related to the vascular permeability factor. Proc Natl Acad Sci U S A 1991;88:9267-9271. doi: 10. 1073/pnas.88.20.9267.

[82] Dewerchin M, Carmeliet P. PIGF: a multitasking cytokine with diseaserestricted activity. Cold Spring Harb Perspect Med 2012;2:a011056. doi: 10.1101/cshperspect.a011056.

[83] Salcedo Mora X, Sanz-Cameno P, Medina J, Martín-Vílchez S, García-Buey L, Borque $\mathrm{MJ}$, et al. Association between angiogenesis soluble factors and disease progression markers in chronic hepatitis C patients. Rev Esp Enferm Dig 2005;97:699-706. doi: 10.4321/S1130-01082005001000003.

[84] Krawczyk M, Zimmermann S, Hess G, Holz R, Dauer M, Raedle J, et al. Panel of three novel serum markers predicts liver stiffness and fibrosis stages in patients with chronic liver disease. PLoS One 2017;12:e0173506. doi: 10. 1371/journal.pone.0173506.

[85] Fischer C, Jonckx B, Mazzone M, Zacchigna S, Loges S, Pattarini L, et al. Anti-PIGF inhibits growth of VEGF(R)-inhibitor-resistant tumors without affecting healthy vessels. Cell 2007;131:463-475. doi: $10.1016 / j$.cell. 2007.08.038.

[86] Van Steenkiste C, Ribera J, Geerts A, Pauta M, Tugues S, Casteleyn C, et al. Inhibition of placental growth factor activity reduces the severity of fibrosis, inflammation, and portal hypertension in cirrhotic mice. Hepatology 2011; 53:1629-1640. doi: 10.1002/hep.24238.

[87] Li X, Yao QY, Liu HC, Jin QW, Xu BL, Zhang SC, et al. Placental growth factor silencing ameliorates liver fibrosis and angiogenesis and inhibits activation of hepatic stellate cells in a murine model of chronic liver disease. J Cell Mol Med 2017;21:2370-2385. doi: 10.1111/jcmm.13158.

[88] Li X, Jin Q, Yao Q, Zhou Y, Zou Y, Li Z, et al. Placental growth factor contributes to liver inflammation, angiogenesis, fibrosis in mice by promoting hepatic macrophage recruitment and activation. Front Immunol 2017;8: 801. doi: 10.3389/fimmu.2017.00801.

[89] Bootcov MR, Bauskin AR, Valenzuela SM, Moore AG, Bansal M, He XY, et al. MIC-1, a novel macrophage inhibitory cytokine, is a divergent member of the TGF-beta superfamily. Proc Natl Acad Sci U S A 1997;94:11514-11519. doi: $10.1073 /$ pnas.94.21.11514.

[90] Eling TE, Baek SJ, Shim M, Lee CH. NSAID activated gene (NAG-1), a modulator of tumorigenesis. J Biochem Mol Biol 2006;39:649-655. doi: 10. 5483/BMBRep.2006.39.6.649.

[91] Moore AG, Brown DA, Fairlie WD, Bauskin AR, Brown PK, Munier ML, et al. The transforming growth factor-ss superfamily cytokine macrophage inhibitory cytokine- 1 is present in high concentrations in the serum of pregnant women. J Clin Endocrinol Metab 2000;85:4781-4788. doi: 10.1210/jcem. 85.12.7007.

[92] Tong S, Marjono B, Brown DA, Mulvey S, Breit SN, Manuelpillai U, et al. Serum concentrations of macrophage inhibitory cytokine 1 (MIC 1 ) as a predictor of miscarriage. Lancet 2004;363:129-130. doi: 10.1016/S01406736(03)15265-8.

[93] Corre J, Hébraud B, Bourin P. Concise review: growth differentiation factor 15 in pathology: a clinical role? Stem Cells Transl Med 2013;2:946-952. doi: 10.5966/sctm.2013-0055.

[94] Si Y, Liu X, Cheng M, Wang M, Gong Q, Yang Y, et al. Growth differentiation factor 15 is induced by hepatitis $C$ virus infection and regulates hepatocelIular carcinoma-related genes. PLoS One 2011;6:e19967. doi: 10.1371/journal. pone.0019967.

[95] Koniaris LG. Induction of MIC-1/growth differentiation factor-15 following bile duct injury. J Gastrointest Surg 2003;7:901-905. doi: 10.1007/s11605003-0037-5.

[96] Chung HK, Kim JT, Kim HW, Kwon M, Kim SY, Shong M, et al. GDF15 deficiency exacerbates chronic alcohol- and carbon tetrachloride-induced liver injury. Sci Rep 2017;7:17238. doi: 10.1038/s41598-017-17574-w.

[97] Liu X, Chi X, Gong Q, Gao L, Niu Y, Chi X, et al. Association of serum level of growth differentiation factor 15 with liver cirrhosis and hepatocellular carcinoma. PLoS One 2015;10:e0127518. doi: 10.1371/journal.pone. 0127518.

[98] Prystupa A, Kiciński P, Luchowska-Kocot D, Błażewicz A, Niedziałek J, Mizerski $G$, et al. Association between serum selenium concentrations and levels of proinflammatory and profibrotic cytokines-interleukin- 6 and growth differentiation factor-15, in patients with alcoholic liver cirrhosis. Int J Environ Res Public Health 2017;14:437. doi: 10.3390/ijerph14040437.

[99] Koo BK, Um SH, Seo DS, Joo SK, Bae JM, Park JH, et al. Growth differentiation factor 15 predicts advanced fibrosis in biopsy-proven non-alcoholic fatty liver disease. Liver Int 2018;38:695-705. doi: 10.1111/liv.13587.

[100] Lee ES, Kim SH, Kim HJ, Kim KH, Lee BS, Ku BJ. Growth differentiation factor 15 predicts chronic liver disease severity. Gut Liver 2017;11: 276-282. doi: 10.5009/gnl16049.
[101] Miyazawa K, Tsubouchi H, Naka D, Takahashi K, Okigaki M, Arakaki N, et al. Molecular cloning and sequence analysis of CDNA for human hepatocyte growth factor. Biochem Biophys Res Commun 1989;163:967-973. doi: 10.1016/0006-291X(89)92316-4.

[102] Comoglio PM, Giordano S, Trusolino L. Drug development of MET inhibitors: targeting oncogene addiction and expedience. Nat Rev Drug Discov 2008; 7:504-516. doi: $10.1038 /$ nrd2530.

[103] Galimi F, Bagnara GP, Bonsi L, Cottone E, Follenzi A, Simeone A, et al. Hepatocyte growth factor induces proliferation and differentiation of multipotent and erythroid hemopoietic progenitors. J Cell Biol 1994;127: 1743-1754. doi: 10.1083/jcb.127.6.1743.

[104] Cahill EF, Kennelly H, Carty F, Mahon BP, English K. Hepatocyte growth factor is required for mesenchymal stromal cell protection against bleomycininduced pulmonary fibrosis. Stem Cells Transl Med 2016;5:1307-1318. doi: $10.5966 /$ sctm. 2015-0337.

[105] Stewart N, Chade AR. Renoprotective effects of hepatocyte growth factor in the stenotic kidney. Am J Physiol Renal Physiol 2013;304:F625-F633. doi: 10.1152/ajprenal.00504.2012.

[106] Esposito C, Parrilla B, Cornacchia F, Grosjean F, Mangione F, Serpieri N, et al. The antifibrogenic effect of hepatocyte growth factor (HGF) on renal tubular (HK-2) cells is dependent on cell growth. Growth Factors 2009;27: 173-180. doi: 10.1080/08977190902834077.

[107] Gallo S, Sala V, Gatti S, Crepaldi T. Cellular and molecular mechanisms of HGF/Met in the cardiovascular system. Clin Sci (Lond) $2015 ; 129$ : 1173-1193. doi: 10.1042/CS20150502.

[108] Cooper CS, Park M, Blair DG, Tainsky MA, Huebner K, Croce CM, et al. Molecular cloning of a new transforming gene from a chemically transformed human cell line. Nature 1984;311:29-33. doi: 10.1038/311029a0.

[109] Schmidt L, Duh FM, Chen F, Kishida T, Glenn G, Choyke P, et al. Germline and somatic mutations in the tyrosine kinase domain of the MET protooncogene in papillary renal carcinomas. Nat Genet 1997;16:68-73. doi: 10.1038/ng0597-68.

[110] Petrini I. Biology of MET: a double life between normal tissue repair and tumor progression. Ann Transl Med 2015;3:82. doi: 10.3978/j.issn.23055839.2015.03.58.

[111] Matsumoto K, Nakamura T. Hepatocyte growth factor: molecular structure and implications for a central role in liver regeneration. J Gastroenterol Hepatol 1991;6:509-519. doi: 10.1111/j.1440-1746.1991.tb00897.x.

[112] Matsuda Y, Matsumoto K, Ichida T, Nakamura T. Hepatocyte growth factor suppresses the onset of liver cirrhosis and abrogates lethal hepatic dysfunction in rats. J Biochem 1995;118:643-649. doi: 10.1093/oxfordjournals. jbchem.a124958.

[113] Lai L, Chen J, Wei X, Huang M, Hu X, Yang R, et al. Transplantation of MSCs overexpressing HGF into a rat model of liver fibrosis. Mol Imaging Biol 2016;18:43-51. doi: 10.1007/s11307-015-0869-x.

[114] Li Z, Mizuno S, Nakamura T. Antinecrotic and antiapoptotic effects of hepatocyte growth factor on cholestatic hepatitis in a mouse model of bileobstructive diseases. Am J Physiol Gastrointest Liver Physiol 2007;292: G639-G646. doi: 10.1152/ajpgi.00292.2006.

[115] Kosai K, Matsumoto K, Funakoshi H, Nakamura T. Hepatocyte growth factor prevents endotoxin-induced lethal hepatic failure in mice. Hepatology 1999;30:151-159. doi: 10.1002/hep.510300102.

[116] Yuge K, Takahashi T, Nagano S, Terazaki Y, Murofushi Y, Ushikoshi H, et al. Adenoviral gene transduction of hepatocyte growth factor elicits inhibitory effects for hepatoma. Int J Oncol 2005;27:77-85. doi: 10.3892/ijo.27.1. 77.

[117] Prystupa A, Kiciński P, Sak J, Boguszewska-Czubara A, Toruń-Jurkowska A, Załuska W. Proinflammatory cytokines (IL-1 $\alpha, \mathrm{IL}-6)$ and hepatocyte growth factor in patients with alcoholic liver cirrhosis. Gastroenterol Res Pract 2015;2015:532615. doi: 10.1155/2015/532615.

[118] Andersen ES, Ruhwald M, Moessner B, Christensen PB, Andersen O, EugenOlsen J, et al. Twelve potential fibrosis markers to differentiate mild liver fibrosis from cirrhosis in patients infected with chronic hepatitis $C$ genotype 1. Eur J Clin Microbiol Infect Dis 2011;30:761-766. doi: 10.1007/s10096010-1149-y.

[119] Yamanouchi H, Fujita J, Yoshinouchi T, Hojo S, Kamei T, Yamadori I, et al. Measurement of hepatocyte growth factor in serum and bronchoalveolar lavage fluid in patients with pulmonary fibrosis. Respir Med 1998;92: 273-278. doi: 10.1016/S0954-6111(98)90108-1.

[120] Konopka A, Janas J, Piotrowski W, Stepińska J. Hepatocyte growth factor-a new marker for prognosis in acute coronary syndrome. Growth Factors 2010;28:75-81. doi: 10.3109/08977190903403984

[121] Wader KF, Fagerli UM, Holt RU, Stordal B, Børset M, Sundan A, et al. Elevated serum concentrations of activated hepatocyte growth factor activator in patients with multiple myeloma. Eur J Haematol 2008;81:380-383. doi: $10.1111 / \mathrm{j} .1600-0609.2008 .01130 . x$ 